\title{
Lack of evidence of generalised sensory neuropathy in patients with carpal tunnel syndrome
}

\author{
M. J . G . H A R R I S O N \\ From the Department of Neurological Studies, The Middlesex Hospital, London
}

S U MMARY Radial and ulnar sensory nerve action potentials were recorded in patients referred for the electrophysiological confirmation of the carpal tunnel syndrome. Comparisons with values obtained in control neurological patients provided no evidence of a generalised neuropathy in such patients, as had previously been suggested.

In 1973, Sedal et al. reported that patients with the carpal tunnel syndrome frequently showed electrophysiological evidence of an ulnar nerve lesion. Even when the patients with clinical indications of an ulnar abnormality were excluded, some $40 \%$ of patients with carpal tunnel syndrome showed a smaller than normal ulnar sensory nerve potential. Sedal et al. concluded that patients with carpal tunnel syndrome might have a subclinical peripheral neuropathy.

Buchthal et al. (1974) reported a similar study of patients with clinical evidence of an isolated carpal tunnel syndrome. Their data showed no evidence of a smaller than normal ulnar sensory nerve action potential in such cases, but they argued that subclinical traumatic lesions of the ulnar nerve were increasingly common after the age of 55 years in patients and in control subjects.

The present study was undertaken to see if there was evidence of subclinical neuropathy or of ulnar neuritis in patients with median nerve compression at the wrist.

\section{Methods}

Patients referred with symptoms suggestive of median nerve compression at the wrist were investigated electrophysiologically. In addition to a median nerve study, ulnar sensory nerve action potentials from fifth digit to wrist (Gilliatt and Sears, 1958), and orthodromic radial sensory nerve action potentials (Downie and Scott, 1967) were measured. The skin temperature was measured at the wrist, and the hand and forearm warmed if the temperature was below $31.5^{\circ} \mathrm{C}$.

Address for reprint requests: Dr M. J. G. Harrison, Department of Neurological Studies, The Middlesex Hospital, London W1 N 8AA. Accepted 26 May 1978
Control values were obtained by carrying out similar measurements in patients with spinal cord disease, motor neurone disease, myopathy and so on-conditions in which no abnormality of upper limb sensory nerve action potentials was to be expected. Severely disabled patients or any individuals using crutches were excluded. All were ambulant.

The electrophysiological criteria for the diagnosis of carpal tunnel compression were the same as those of Sedal et al. (motor distal latencies $>5.0 \mathrm{~ms}$; sensory distal latency $>4.0 \mathrm{~ms}$; median sensory nerve action potential under $8.0 \mu \mathrm{V}$ ). In addition, a distal latency exceeding $5.5 \mathrm{~ms}$ at threshold stimulation was considered indicative of an abnormality even when other findings were within normal limits. The patients referred as possibly suffering from the carpal tunnel syndrome were grouped according to whether or not their EMG studies confirmed the presence of a lesion.

\section{Results}

Ulnar sensory nerve action potentials were recorded in 31 control subjects and in 89 patients with a referral diagnosis of carpal tunnel syndrome. In 60 of these there were electrophysiological findings diagnostic of median nerve compression.

There was no difference between the groups either for age or for amplitude of the sensory nerve action potential (SAP) (Table 1). An analysis of covariance (Fig. 1) showed no difference between the carpal tunnel syndrome patients and the control subjects.

Radial SAPs were recorded in 59 control subjects, in 50 patients with a confirmed diagnosis of 
carpal tunnel syndrome, and in 23 patients with symptoms but no EMG evidence of carpal tunnel syndrome. No differences were found in the age structure or the SAP amplitudes of the three groups (Table 2). An analysis of covariance (Fig. 2) again showed no difference between the carpal tunnel patients and control subjects.

Table 1 Mean ages of subjects and amplitude of ulnar sensory action potentials

\begin{tabular}{lccc}
\hline Group & Number & Age $(y r) \pm S D$ & Amplitude $(\mu V) \pm S D$ \\
\hline $\begin{array}{l}\text { Control subjects } \\
\begin{array}{l}\text { Carpal tunnel } \\
\text { syndrome }\end{array}\end{array}$ & 31 & $52.1 \pm 14$ & $12.1 \pm 6.6$ \\
$\begin{array}{l}\text { confirmed } \\
\begin{array}{l}\text { Carpal tunnel } \\
\text { syndrome } \\
\text { unconfirmed }\end{array}\end{array}$ & 60 & $55.9 \pm 13$ & $14.1 \pm 8.1$ \\
\hline
\end{tabular}
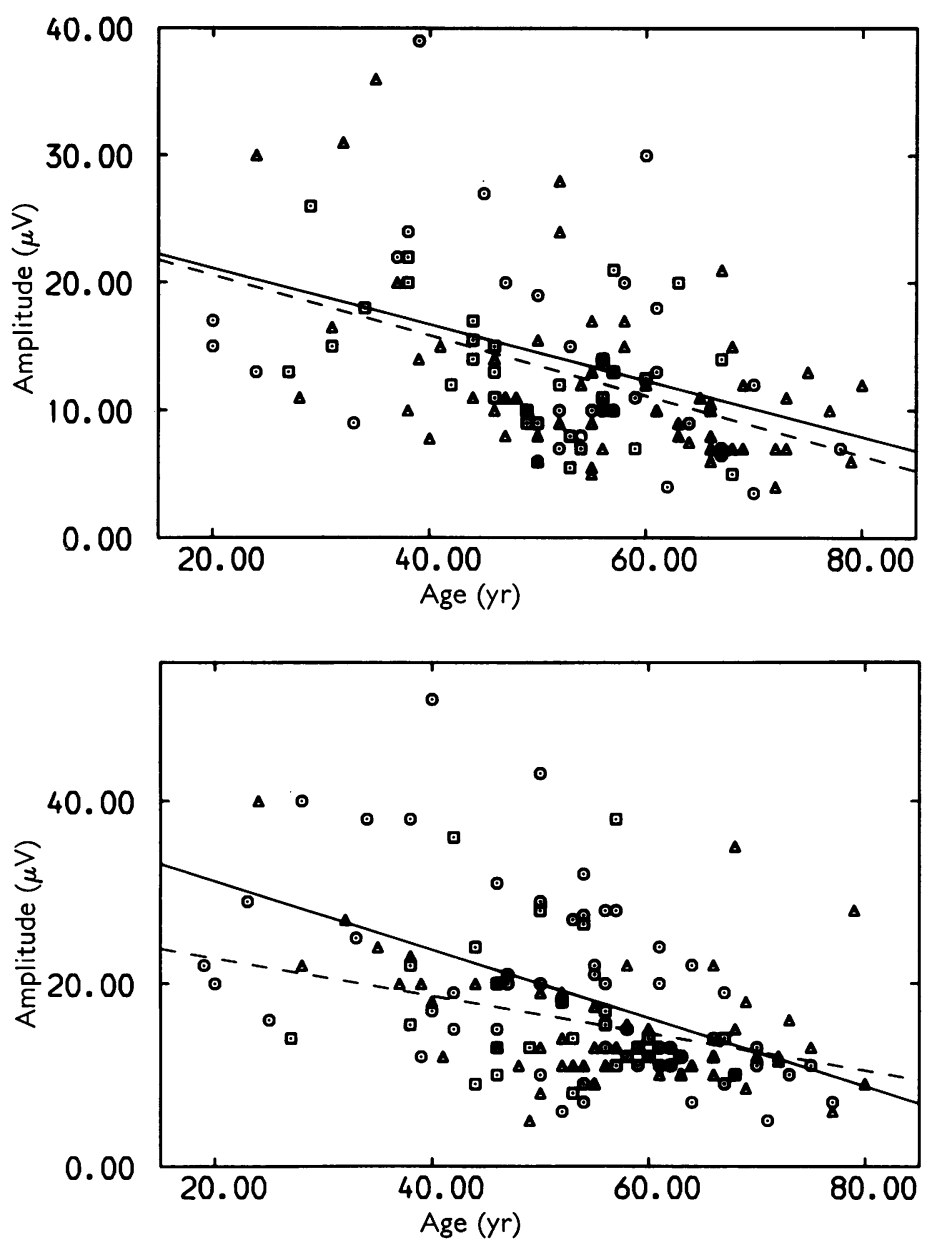

Fig. 1 Amplitude of ulnar nerve sen:ory action potential at wrist as a function of age; $\Delta=$ carpal tunnel patients confirmed by EMG studies, $\square=$ carpal tunnel patients with normal $E M G$ results, $\bigcirc=$ control subjects, $-=$ regression line for control subjects, - ..-- = regression line for confirmed cases of carpal tunnel syndrome.

Fig. 2 Amplitude of radial nerve sensory action potential at wrist as a function of age; symbols as for Fig. 1 . 
studied, it seems equally possible that their patients had a high incidence of traumatic ulnar neuritis, and motor studies provided evidence of such a lesion at the elbow in $50 \%$. The results of Buchthal's study (1974) and the present findings provide no support for either suggestion, however, with no evidence of an abnormality of ulnar sensory nerve action potentials. The present study, by measuring also radial nerve SAPs, provides further evidence against a generalised sensory neuropathy in the carpal tunnel syndrome. The discrepancy with the Australian group's findings is not readily explained, the data for controls in the different centres being very close and the age structure of the populations studied apparently very similar. It remains possible that an important number of more complicated severe cases are referred to their department, but there is no direct evidence of this.

The routine recording of ulnar or radial nerve SAPs in patients thought to have the carpal tunnel syndrome has traditionally served two purposes. Firstly it has been considered a useful screening procedure to detect the rare patient in whom a specific neuropathy, such as that caused by diabetes mellitus, has come to light only with the symptoms of a carpal tunnel syndrome, or is complicating the assessment of the syndrome. The second purpose concerns the need to monitor the effects of age and temperature on the amplitude of nerve SAPs when trying to decide if a patient has indeed got a significant abnormality in the median nerve. The present finding of normal radial and ulnar nerve SAPs in patients with a proven carpal tunnel syndrome implies that it is reasonable to continue to use these measures in this way.

I am grateful to Dr B. Newman for help with statistical handling of the data.

\section{References}

Buchthal, F., Rosenfalck, A., and Trojaborg, W. (1974). Electrophysiological findings in entrapment of the median nerve at wrist and elbow. Journal of Neurology, Neurosurgery, and Psychiatry, 37, 340-360.

Downie, A. W., and Scott, T. R. (1967). An improved technique for radial nerve conduction studies. Journal of Neurology, Neurosurgery, and Psychiatry, 30, 332-336.

Gilliatt, R. W., and Sears, T. A. (1958). Sensory nerve action potentials in patients with peripheral nerve lesions. Journal of Neurology, Neurosurgery, and Psychiatry, 21, 109-118.

Sedal, L., McLeod, J. G., and Walsh, J. C. (1973). Ulnar nerve lesions associated with the carpal tunnel syndrome. Journal of Neurology, Neurosurgery, and Psychiatry, 36, 118-123. 